\title{
O PAPEL DO TUTOR NO DESENVOLVIMENTO DO PENSAMENTO CRÍTICO E RESOLUÇÃO DE PROBLEMAS
}

\author{
Rosa M. Vasconcelos ${ }^{1}$, Magda O. Pinheiro ${ }^{2}$, Luís Amaral ${ }^{3}$
}

\begin{abstract}
The School of Engineering of the University of Minho adapted to the requirements of the Bologna Process through various measures. Among these, the adoption of the methodology of teaching and learning Project-Led Engineering Education is to be highlighted, where the active role of the learner and the tutor's role as "guide" throughout the project is promoted and appreciated. In order to understand whether the role of the tutor is being performed as expected, a series of questionnaire surveys were conducted. In this study instrument, issues within the perception of students on the role of the tutor in Project-Led Engineering Education, on the promotion of critical thinking and on the appreciation of problem solving were addressed.
\end{abstract}

Index Terms - Projeto; tutor; pensamento crítico; resolução de problemas.

\section{ENSINO POR PROJETO}

O Ensino Superior, em Portugal, sofreu profundas mudanças nas últimas décadas. Uma das mais significativas foi impulsionada pela Declaração de Bolonha, onde foi exigido às instituições de Ensino Superior reestruturações curriculares e a utilização de novas metodologias de ensinoaprendizagem [1].

Assim, a Universidade do Minho adequou-se às exigências, reorganizou os seus ciclos de estudo, reajustou os anos curriculares, implementou o sistema de créditos ECTS e submeteu-se a avaliação externa [2].

A Escola de Engenharia da Universidade do Minho optou ainda por ajustar muitos dos seus $1 .^{\circ}$ Ciclos e Mestrados Integrados segundo a metodologia de Ensino por Projeto. Este modelo de ensino-aprendizagem envolve os discentes em Projetos ao longo da sua formação académica, onde simulam situações de projeto possíveis de ocorrer em ambiente profissional. Segundo Guedes et all "a metodologia de aprendizagem por Projeto está relacionada com uma visão interdisciplinar e mesmo transdisciplinar do saber. O facto de se centrar na resolução de problemas introduz uma dinâmica de integração e síntese entre teoria e prática, adequando-a à identificação de problemas pertinentes e à construção de soluções ajustadas" [3].

O Ensino por Projeto foi desenvolvido, inicialmente, na Universidade de Twente, na Holanda, onde se procurou promover a aprendizagem através da resolução de problemas [4]. Deste modo, os alunos eram envolvidos em problemas reais ou possíveis da atividade profissional, motivando-os a fazer uma ligação entre a teoria e a prática e uma aplicação dos conhecimentos mais teóricos, dando um novo sentido à aprendizagem no Ensino Superior [4].

Esta metodologia de ensino exige muito quer dos alunos, quer dos docentes, bem como um plano curricular ajustado a este método.

Sendo uma metodologia de ensino-aprendizagem extremamente ativa, os docentes têm que se adaptar constantemente aos novos desafios e problemáticas, bem como estudar e validar as soluções adotadas pelos grupos de trabalho.

No Ensino por Projeto, os docentes/tutores são definidos como facilitadores de aprendizagem. Promovem a discussão de ideias, novos paradigmas e desenvolver pensamento crítico e de resolução de problemas nos discentes. No Projeto, os tutores apoiam o grupo a encontrar e construir a solução do problema [5].

Os Projetos são incluídos numa unidade curricular, semestral, onde os discentes têm de englobar todos os conhecimentos adquiridos nas disciplinas do curso.

Partindo deste paradigma, este estudo analisa o papel do tutor no desenvolvimento do pensamento crítico e resolução de problemas, naquele contexto, bem como as "relações de classes" inerentes entre tutor-aluno e aluno-aluno.

\section{Pensamento Crítico}

As origens do Pensamento Crítico remontam à Grécia Antiga, onde Sócrates desenvolveu o Pensamento Socrático, apoiado num raciocínio indutivo e no diálogo, como processo de ensino [6].

Atualmente, a definição de Pensamento Crítico pode ser compreendida em três áreas de conhecimento distintas:

- Originária da Filosofia, que defende a aproximação ao "bom pensamento", realçando os aspetos lógicos do raciocínio [6];

- Descendente da Psicologia Cognitiva, que define o Pensamento Crítico como uma capacidade de pensamento de ordem superior, focando a atenção numa aprendizagem apropriada e em processos educativos [7];

- Procedente da Pragmática (ou Pedagogia Crítica), onde o Pensamento Crítico é compreendido como uma capacidade de força de trabalho necessária no futuro mercado de trabalho. Este prisma valoriza a cidadania

\footnotetext{
${ }^{1}$ Rosa M. Vasconcelos, Vice-Presidente da Escola de Engenharia da Universidade do Minho, Guimarães, Portugal, rosa @ det.uminho.pt

${ }^{2}$ Magda O. Pinheiro, Conselho Pedagógico da Escola de Engenharia da Universidade do Minho, Guimarães, Portugal, magda@eng.uminho.pt

${ }^{3}$ Luis Amaral, Departamento de Sistemas de Informação, Universidade do Minho, Guimarães, Portugal, amaral@dsi.uminho.pt
} 
democrática e crítica como um objetivo educacional e um foco na transformação da sociedade [8].

Apesar das diferentes correntes, o Pensamento Crítico deve ser compreendido como o uso de capacidades cognitivas que aumentam a probabilidade de se obterem resultados desejáveis. Assim, o Pensamento Crítico é intencional, racional e dirigido para uma meta, podendo essa meta ser a resolução e problemas ou uma tomada de decisão [8].

\section{ResoluÇão de Problemas}

O método de Resolução Criativa de Problemas pressupõe que todos os problemas são solucionáveis, bastando para isso a adoção de uma atitude criativa [9].

A técnica de Resolução Criativa de Problemas foi criada, inicialmente por Parnes, em 1967, e fundamenta-se no uso integrado do pensamento divergente e convergente ao longo das seis etapas do processo de resolução de problemas e complementar: (1) Encontrar o Problema; (2) Encontrar Factos; (3) Definir Problemas; (4) Encontrar Ideias; (5) Encontrar Soluções e (6) Encontrar Aceitação [10].

É um método extremamente útil no desenvolvimento de competências criativas e cognitivas como um todo, isto é, permite construir competências intelectuais e fortalecer processos mentais que aumentam a capacidade do indivíduo para enfrentar as mudanças quer do quotidiano pessoal, quer profissional [11].

O problema é o desafio resultante de uma situação conflituosa e desconcertante, que pretende incentivar o aluno, neste caso, a resolver. Obrigando-o a estruturar o seu pensamento na resolução do problema, a selecionar o factos/informações mais relevantes e, por fim, a uma tomada de decisão na resolução e/ou criação de produto [12].

\section{RELAÇÕES DE CLASSES}

A definição de "relações de classes", desenvolvida por Bernstein [13], envolve desigualdades na distribuição de poder e nos princípios de controlo entre grupos sociais, princípios que são realizados na criação, distribuição, reprodução e legitimação dos valores físicos e simbólicos que têm a sua fonte na divisão social do trabalho. Estes princípios regulam as relações no interior dos grupos sociais e entre eles, portanto, formas de consciência.

As relações de classes "geram, distribuem, reproduzem e legitimam formas distintas de comunicação, as quais transmitem códigos dominantes e dominados, e que, no processo de adquirir esses códigos, os sujeitos são por eles diferentemente posicionados" [13].

Assim, o discurso pedagógico utilizado será fundamental para o desenvolvimento do pensamento crítico e técnica de Resolução Criativa de Problemas.

\section{Metodologia}

Com o intuito de perceber o papel do tutor no desenvolvimento do pensamento crítico e resolução de problemas, foi efetuado este estudo que insere uma pesquisa bibliográfica e uma análise estatística dos inquéritos realizados pelos alunos, no âmbito da unidade curricular Projeto Interdisciplinar.

Estes inquéritos foram realizados entre os anos letivos 2010/2011 e 2012/2013, nos 7 projetos interdisciplinares do Mestrado Integrado em Engenharia Têxtil, da Universidade do Minho, isto é, do $1 .^{\circ}$ ao $4 .^{\circ}$ ano do plano curricular.

Foram efetuados 111 inquéritos, onde são analisadas as experiências de aprendizagem por projeto. $\mathrm{O}$ questionário era composto por 40 perguntas fechadas e 2 perguntas abertas. A 39 perguntas fechadas foi aplicado uma escala que varia entre 1 e 5 , correspondente a (1) Discordo totalmente; (2) Discordo; (3) Nem concordo, nem discordo; (4) Concordo; (5) Concordo totalmente. Será um dos parâmetros dessas perguntas fechadas - $\mathrm{O}$ desenvolvimento do pensamento crítico e resolução de problemas - que será analisado estatisticamente, com o suporte do programa estatística IBM SPSS 22. Este parâmetro compreendia 4 questões onde era questionado o papel do tutor no envolvimento da execução do projeto, nomeadamente, (1) "O tutor apoia a equipa na investigação dos conceitos relevantes para o projeto"; (2) "O tutor incentiva a equipa a analisar criticamente a informação"; (3) "O tutor realça que todos os elementos da equipa são responsáveis pelo processo e pelo resultado final do projeto"; (4) "O tutor estimula o desenvolvimento da autonomia dos alunos".

\section{RESULTADOS}

Dos 111 inquéritos por questionário, 31 foram realizados no ano letivo 2012/2013, 32 foram efetuados no ano letivo 2011/2012 e 48 no ano letivo 2010/2011 (tabela I).

\begin{tabular}{lll} 
& $\begin{array}{l}\text { TABELA I } \\
\text { ANO LETIVO }\end{array}$ & \\
\hline Ano & Frequência & Percentagem \\
\hline $2012 / 2013$ & 31 & 27,9 \\
$2011 / 2012$ & 32 & 28,8 \\
$2010 / 2011$ & 48 & 43,2 \\
\hline
\end{tabular}

Conseguiu-se analisar 23 inquéritos do Projeto Interdisciplinar I, 7 questionários do Projeto Interdisciplinar II, 20 inquéritos do Projeto Interdisciplinar III, 12 inquéritos do Projeto Interdisciplinar IV, 21 inquéritos do Projeto Interdisciplinar V e 28 inquéritos de Projeto Interdisciplinar VII (tabela II).

TABELA II

PROJETO INTERDISCIPLINAR

\begin{tabular}{lll}
\hline Ano & Frequência & Percentagem \\
\hline PI I & 23 & 20,7 \\
PI II & 7 & 6,3 \\
PI III & 20 & 18 \\
\hline
\end{tabular}




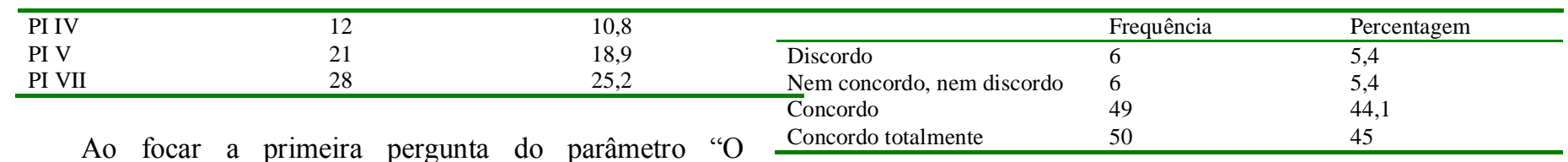
desenvolvimento do pensamento crítico e resolução de problemas, deparamo-nos com a problemática do apoio na investigação dos conceitos relevantes para o projeto, onde se destacam as respostas de anuência com a questão. Tendo respondido $43,2 \%$ dos alunos que concordava que o tutor o tivesse apoiado na investigação dos conceitos relevantes para o projeto e $39,6 \%$ afirmando que concordam totalmente (tabela III).

TABELA III

O TUTOR APOIA A EQUIPA NA INVESTIGAÇÃO DOS CONCEITOS RELEVANTES PARA O PROJETO

\begin{tabular}{lll}
\hline Ano & Frequência & Percentagem \\
\hline Discordo & 1 & 0,9 \\
Nem concordo, nem discordo & 18 & 16,2 \\
Concordo & 48 & 43,2 \\
Concordo totalmente & 44 & 39,6 \\
\hline
\end{tabular}

Quanto à problemática do incentivo à equipa, por parte do tutor, e à análise crítica da informação, sobressai de modo positivo os $45 \%$ do "concordo totalmente" e $40,5 \%$ de "concordo", tal como pode ser comprovado na tabela IV.

TABELA IV

O TUTOR INCENTIVA A EQUIPA A ANALISAR CRITICAMENTE A INFORMAÇÃO

\begin{tabular}{lll}
\hline & Frequência & Percentagem \\
\hline Discordo & 4 & 3,6 \\
Nem concordo, nem discordo & 12 & 10,8 \\
Concordo & 45 & 40,5 \\
Concordo totalmente & 50 & 45 \\
\hline
\end{tabular}

$\mathrm{Na}$ tabela $\mathrm{V}$ podemos verificar o papel do tutor na responsabilização de todos os elementos da equipa pelo processo e pelo resultado final do projeto, onde se pode constatar, onde se salienta $45 \%$ de concordância total e $42,3 \%$ de concordância.

TABELA V

O TUTOR REALÇA QUE TODOS OS ELEMENTOS DA EQUIPA SÃO RESPONSÁVEIS PELO PROCESSO E PELO RESULTADO FINAL DO PROJETO

\begin{tabular}{lll}
\hline & Frequência & Percentagem \\
\hline Discordo & 2 & 1,8 \\
Nem concordo, nem discordo & 12 & 10,8 \\
Concordo & 47 & 42,3 \\
Concordo totalmente & 50 & 45 \\
\hline
\end{tabular}

$\mathrm{Na}$ última questão do parâmetro referente ao desenvolvimento do pensamento crítico e resolução de problemas, destacam-se, uma vez mais, as respostas de "concordo" e "concordo totalmente", tendo 44,1\% e 45\%, respetivamente (tabela VI).

TABELA VI

O TUTOR ESTIMULA O DESENVOLVIMENTO DA AUTONOMIA DOS ALUNOS

\section{CONCLUSÕES}

A Universidade do Minho adequou-se a todas as exigências e desafios do Processo de Bolonha, destacando-se a reestruturação curricular, a implementação de novas metodologias de ensino-aprendizagem, a adoção do sistema de créditos ECTS e a submissão a avaliação externa

O Ensino por Projeto, adotado pela Escola de Engenharia em muitos dos seus $1 .^{\circ}$ Ciclos e Mestrados Integrados, tem proporcionado aos alunos uma experiência similar aos projetos em ambiente profissional.

Quanto ao papel do tutor nos respetivos projetos é de salientar a avaliação extremamente positiva da percepção que os alunos têm do trabalho dos tutores. A soma das respostas positivas "Concordo" e "Concordo totalmente" assumem valores entre os $80 \%$ e $90 \%$, em todas as questões.

Só na primeira questão, "O tutor apoia a equipa na investigação dos conceitos relevantes para o projeto" é que o valor superior é o "Concordo", com 43,2\%, muito próximo do "Concordo totalmente", com 39,6\%. Nas restantes questões, a resposta mais evidenciada foi o "Concordo totalmente", sendo a percentagem igual nas três questões, $45 \%$.

Pela percepção recolhida pelos discentes pode-se concluir que a implementação dos desafios propostos tem sido efetuada com sucesso na metodologia de ensinoaprendizagem de ensino por projeto.

\section{ACKNOWLEDGMENT}

This work was partly funded by FEDER funds through the Operational Competitiveness Program (COMPETE) and by FCT with the projects PEst-C/CTM/UI0264/2011 and FCOMP- 01-0124-FEDER-022674.

\section{BIBLIOGRAFIA \\ 1] Almeida, L, S., Vasconcelos, R. M. and Mendes, T, "O abandono dos Estudantes no Ensino Superior: Um estudo na Universidade do Minho," Revista Galego-Portuguesa de Psicoloxía e Educación, vol. $16(1,2)$, pp. 111-120, 2008, ISSN 1138-1663.}

[2] Universidade do Minho, "Relatório de concretização do processo de Bolonha na Universidade do Minho," Universidade do Minho, Braga, 2008.

[3] Guedes, M. G., Lourenço, J. M., Filipe, A. I., Almeida, L. and Moreira M. A., Bolonha Ensino e Aprendizagem por Projeto. V. N. de Famalicão: Centro Atlântico, Lda., 2007, p. 32.

[4] Powell, P. and Weenk, W, Project-Led Engineering Education. LEMMA Publishers, 2003.

[5] van Hattum-Janssen, N. and Vasconcelos, R. M., "The role of the tutor 
in Project-Led Education: the developmente of an evaluation instrument," INTERTECH, pp. 27-31, 2008.

[6] Arends, R. I., Aprender a ensinar. Lisboa: MacGraw-Hill., 1995.

[7] Halpern, D.F., "Teaching critical thinking for transfer across domains, dispositions, skills, structure training, and metacognitive monitoring," American Psychologist, vol. 53, pp. 449-455, 1998.

[8] Halpern, D. F., Thought and knowledge: An introduction to critical thinking, 3rd ed. Mahwah: Lawrence Erlbaum Associates, Publishers, 1996.

[9] Forbes, R., The Creative Problem Solver's Toolbox: A complete course in the art of creating solutions to problems of any kind.: Solutions Through Innovation, Corvallis, OR , 1993.

[10] Alencar, E. M., O processo da criatividade: Produção de ideias e técnicas criativas.: Makron, 2000, 85-346-1148-3.

[11] Switalski, L. B., Evaluating and organizing thinking tools in relationship to CPS framework, Buffalo State College,International Center for Studies in Creativity State University of NewYork, Ed., 2003.

[12] Guilford, J. P., The nature of human intelligence. New york: MacGraw- Hill, 1967.

[13] Bernstein, B., A estruturação do discurso pedagógico. Petrópolis: Editora Vozes Ltda., 1996. 